Original Research

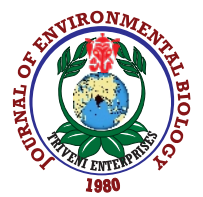

DOI : http://doi.org/10.22438/jeb/42/4(SI)/MRN-1534a
Journal website : www.jeb.co.in ^ E-mail : editor@jeb.co.in

\section{Journal of Environmental Biology}

p-ISSN: 0254-8704 e-ISSN: 2394-0379 CODEN: JEBIDP

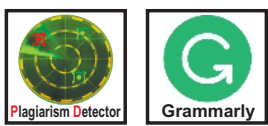

\title{
Estimation of carbon footprint in Tamil Nadu Agricultural University, Coimbatore
}

\author{
C.G. Karishma ${ }^{1 *}$, S.V.Kottiswaran², A. Balasubramanian ${ }^{3}$ and B. Kannan ${ }^{1}$ \\ 'Soil \& Water Conservation Engineering, Agricultural Engineering Collage \& Research Institute, TNAU, Coimbatore-641 003, India \\ ${ }^{2}$ Agricultural Engineering Collage \& Research Institute, TNAU, Coimbatore-641 003, India \\ ${ }^{3}$ Department of Silviculture, Forest College and Research Institute (FC\&RI), Mettupalayam-641301, India \\ *Corresponding Author Email : karishmaswce@gmail.com
}

\section{Abstract}

Aim: A study was conducted in the Eastern block of Tamil Nadu Agricultural University, Coimbatore to estimate the carbon footprint from various sources comprising of transport, human population, diesel generator and electricity use.

Methodology: The data were collected based on the questionnaire developed. Empirical equations were used for computation and data were statistically analysed.

Results: Carbon footprint analysis in the selected buildings revealed that, the equivalent carbon emission from power, diesel generators, human population and transport were 291, 14.17, 78.72 and 36.43 tonnes per year, respectively. It was inferred that emission from power use was greater in comparison with emission from transport, human population and dieselgenerators.

Interpretation: For a diversified source of emission in a university, reduction in anthropogenic emissions can be achieved by increasing the capacity of carbon sinks, i.e., through carbon sequestration and switching to low-carbon energy sources.

Key words: Climate change, Carbon footprint, Carbon sink, Low-carbon energy sources

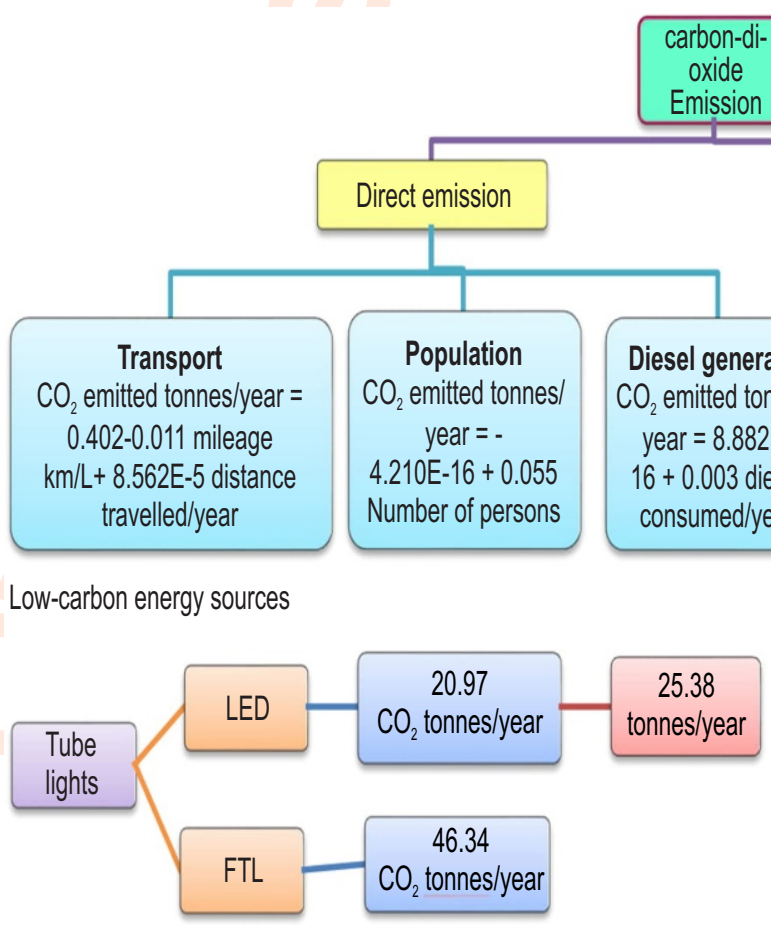

How to cite : Karishma.C.G., S.V.Kottiswaran, A.Balasubramanian and B. Kannan: Estimation of carbon footprint in Tamil Nadu Agricultural University, Coimbatore. J. Environ. Biol., 42, 1134-1140 (2021). 


\section{Introduction}

Most of the observed increase in global average temperature is due to steady increase of $\mathrm{CO}_{2}$ in the atmosphere. Greenhouse gas emissions cause heat to be trapped by the earth's atmosphere, and this has been the main driving force behind global warming. The main sources of such emissions are natural systems and human activities. Yue and Gao, statistically analysed global greenhouse gas emissions from natural systems and anthropogenic activities and concluded that the earth's natural system can be considered as self balancing and that anthropogenic emissions add extra pressure to the earth system (Yue and Gao, 2018). Poverty, population pressure, agricultural expansion and intensification and development of infrastructure have been suggested as major threats to biodiversity in the tropics (Davidar et al., 2010) which increases the pressure on the remaining forests (Bargali et al., 1992a, b; 1993; Kittur et al., 2014, Baboo et al., 2017; Bargali et al., 2018).

Continuous increase in the human population together with livestock populations, the pressure on these forests in terms of intensive livestock grazing, fuel wood and timber harvesting for their energy and income generation are mounting and consequently resulting in the reduced carrying capacity of these forests (Davidar et al., 2010; Sagar and Singh 2004) which increased the change in local atmosphere (Arora et al., 2011; Bargali et al., 2019; Manral et al., 2020). Even $\mathrm{CH}_{4}$ and chlorofluorocarbons have significant importance but their concentration is significantly less than $\mathrm{CO}_{2}$. Anthropogenic activity has been increasing the concentration of greenhouse gases in the atmosphere. Following the rule that only measurable is manageable, ministration of greenhouse gas intensiveness of different products, bodies, and processes is going on worldwide (Pandey, 2011). The Carbon footprint is made up of the sum of two parts, the direct and indirect or secondary footprint (Tukker and Jansen, 2006).

Electricity production generates the largest share of greenhouse gas emissions. Approximately, $67 \%$ of our electricity comes from burning fossil fuels, mostly coal and natural gas (USEIA, 2016). Transportation contributes $26 \%$ of greenhouse gas emission. Emissions from transportation primarily come from the exhaust of cars, trucks, ships, trains and planes. Over $90 \%$ of the fuel used for transportation is petroleum based, which includes gasoline and diesel (Kahn Ribeiro, et al., 2007). Letete,et al. (2011) had estimated carbon footprint for the year 2007 at University of Cape Town's to be about 83400 tons CO2 equivalent, with campus energy consumption, Transportation and Goods Services contributes about $81 \%, 18 \%$ and one $\%$ footprint. Electricity consumption alone contributes about $80 \%$ of all the emissions associated with university activities. Carbon Dioxide from various emission inventories in Institute of Science and Technology, Arakkunnam was carried out by Mary Lissy (2012) and suggested remedial measures for the reduction of emissions as a part of social commitment. Utaraskul, (2015) had studied the Carbon footprint of 35 students in Environmental
Science Program, Faculty of Science and Technology, Suan Sunandha Rajabhat University based on three criteria transportation, food consumption and energy consumption by using electric appliances. Considering all these factors a study was conducted in the Eastern side of Tamil Nadu Agricultural University, Coimbatore to estimate the carbon footprint from various sources comprising of transport, human population, diesel generator and electricity use.

\section{Materials and Methods}

The study was carried out in the eastern block of Tamil Nadu Agricultural University, Coimbatore. The study area is 77606 sqm comprising of 29 buildings.

Data collection: The data were collected from 29 buildings based on the semi-structured questionnaire developed and interaction with the individuals (respondents).

\section{Estimation of carbon footprint}

Estimation of $\mathrm{CO}_{2}$ dioxide emission from electrical appliances:

Total units consumed by electrical appliances $(x)=$ $b^{*} c^{*} d / 1000(k W h)$

Type of fitting (lights, fans etc.,) (a) Wattage of the fitting. (b), Installed fixtures in numbers. (c), Average working hours in a year. (d), $\mathrm{CO}_{2}$ emission factor. (e)

$x^{*} e$

Total $\mathrm{CO}_{2}$ emission from electrical appliances = (2)

Estimation of $\mathrm{CO}_{2}$ emission from diesel generators:

Total $\mathrm{CO}_{2}$ emission from generators $=b^{*} \mathrm{c}$.

Diesel consumed litres per year (b) $\mathrm{CO}_{2}$ emission factor $(\mathrm{C}$

Estimation of $\mathrm{CO}_{2}$ emission from human population:

Total $\mathrm{CO}_{2}$ emission from human beings $=\mathrm{a}^{*} \mathrm{~b}^{*} \mathrm{c}^{*} \mathrm{~d}$ (4)

Total number of individuals in the building. (a) Average working hours in a week; (b) Average working days in a year. (c) Per capita $\mathrm{CO}_{2}$ emission

\section{(0.9 kilograms of $\mathrm{CO}_{2}$ for each day per person).}

Estimation of vehicular $\mathrm{CO}_{2}$ emission

Total $\mathrm{CO}_{2}$ emission from vehicles $=\mathrm{C}^{*} \mathrm{e}$

Distance travelled. (C), $\mathrm{CO}_{2}$ emission factor. (e)

[To be taken into consideration: type of vehicle (two wheeler, four wheeler etc.,), type of fuel (diesel or petrol) and mileage of vehicle]. 
Note: The emission factors for vehicles were assumed from the report given by "Automotive Research Association of India", 2007. When the emission factors were unavailable in the database, the constant emission factors for petrol and diesel were assumed. Total $\mathrm{CO}_{2}$ emission = Electrical appliances carbon dioxide emission $+\mathrm{CO}_{2}$ emission from diesel generators + Human $\mathrm{CO}_{2}$ emission $+\mathrm{CO}_{2}$ emission from vehicles

Statistical analysis: The data obtained were statistically analysed to evaluate possible significance of independent variables to dependant variable.

Multiple linear regression model: A model which depicts the influence of two or more independent variables on the dependent variable. In this model, the dependent variable will be a continuous variable and independent variables can be continuous, discrete andcategorical.

Multiple linear regression model is represented by:

$$
Y=a+b_{1} x_{1}+b_{2} x_{2}+\ldots \ldots \ldots b_{p} x_{p}
$$

Where, $a$ is the constant and $b_{1}, b_{2}$ etc. are the partial regression coefficients, $x_{1}, x_{2}, x_{p}$ are the $p$ independent variables. Partial regression coefficients show the influence of independent variable to dependent variable. This can be tested for its significance by applying Student's t-test, the coefficient of multiple determination $\mathrm{R}^{2}$ is the contribution of all independent variables considered in the model to dependent variable.

\section{Results and Discussion}

The power use in buildings and the equivalent carbon emitted was computed using Eq.1 and 2, respectively. Fig. 1. Shows that the Carbon emission was highest in the department of Agricultural Engineering College and Research Institute (24.82 tonnes per year), followed by the crop physiology department (19.57 tonnes per year) and technology parks. Total power consumed $341865 \mathrm{kWh} / \mathrm{year}$ and the equivalent Carbon emission was 291 tonnes per year in the study area.

One of the options to reduce carbon emission is to replace the existing fluorescent tube lights in the buildings with LED which can bring about a considerable reduction in $\mathrm{CO}_{2}$ emission as well as cost. Table 1 reveals that the carbon emission from FTL and LED was 46.342 and 20.966 tonnes per year respectively. It is evident that there is a difference in emission reduction of 25.376 tonnes of $\mathrm{CO}_{2}$ per year. The unit saved by replacing $F T L$ to LED is $29853.750 \mathrm{kWh}$ per year. It is interpreted that out of 29 buildings only 10 buildings used diesel generator and the overall diesel consumption per year was 5340 I, with equivalent $\mathrm{CO}_{2}$ emission of 14.17 tonnes per year. Fig. 2 reveals that the maximum emission was found in Physical Sciences and Information Technology Department. The total population in the study area was 1428 and the $\mathrm{CO}_{2}$ emitted from the population in different buildings was 78.72 tonnes per year. Fig. 3 represents the $\mathrm{CO}_{2}$ emission plotted against population in the buildings. It is

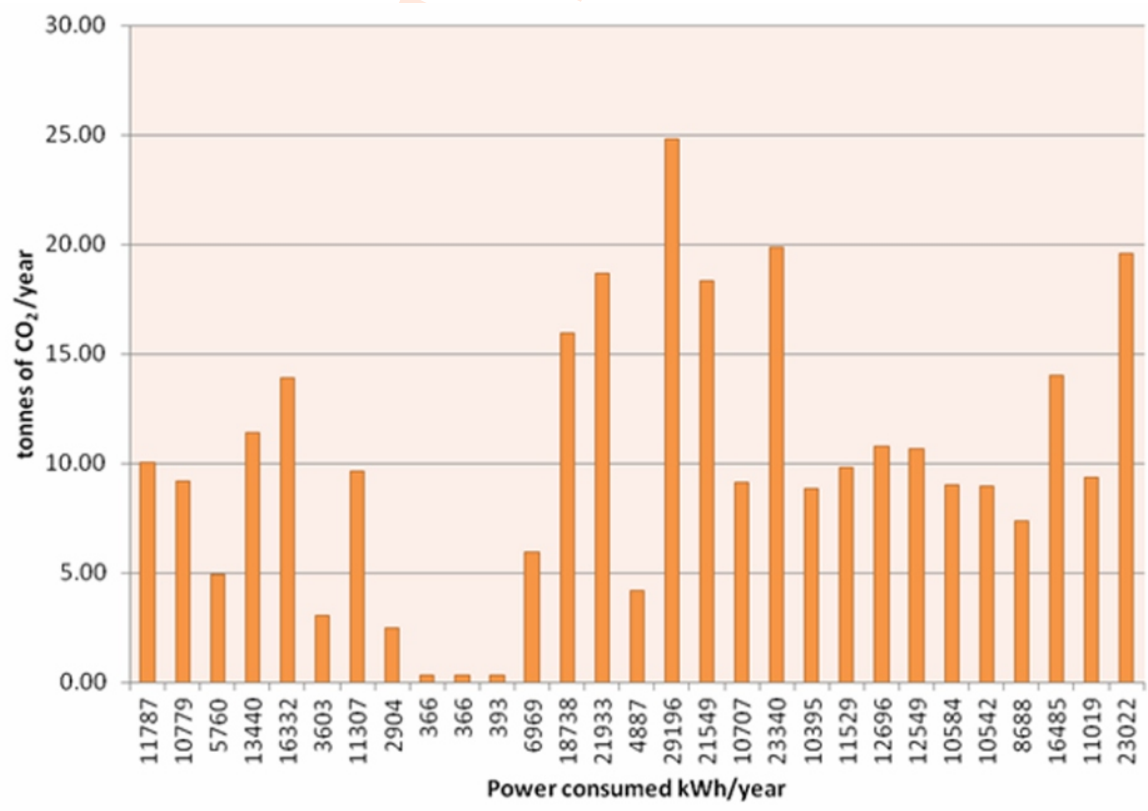

Fig.1: Equivalent carbon dioxide emission from power use. 


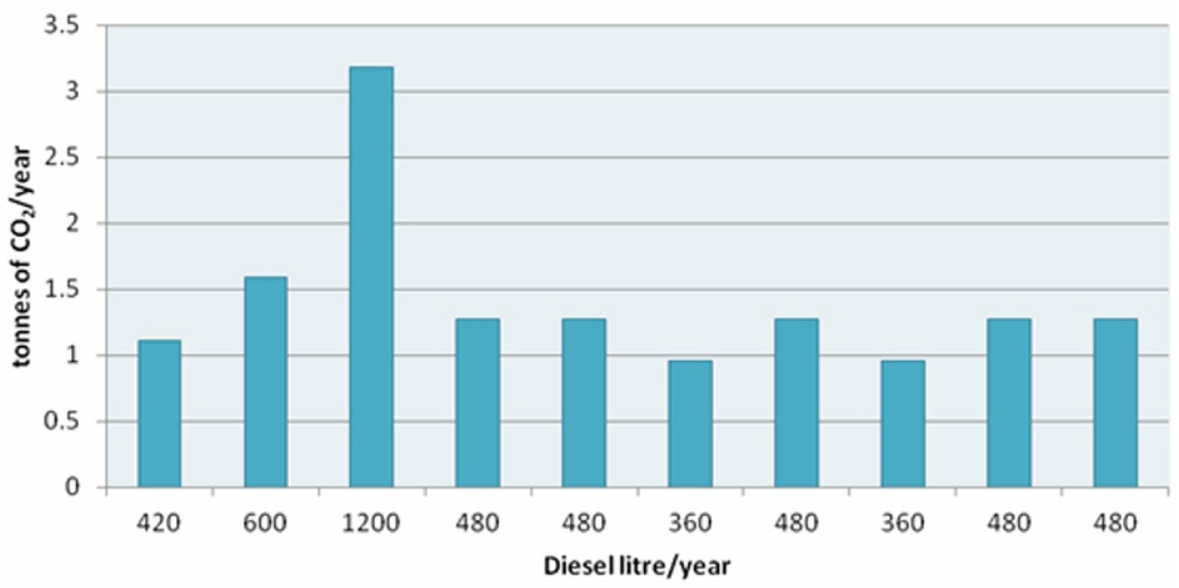

Fig. 2: Equivalent carbon dioxide emission from diesel generators.

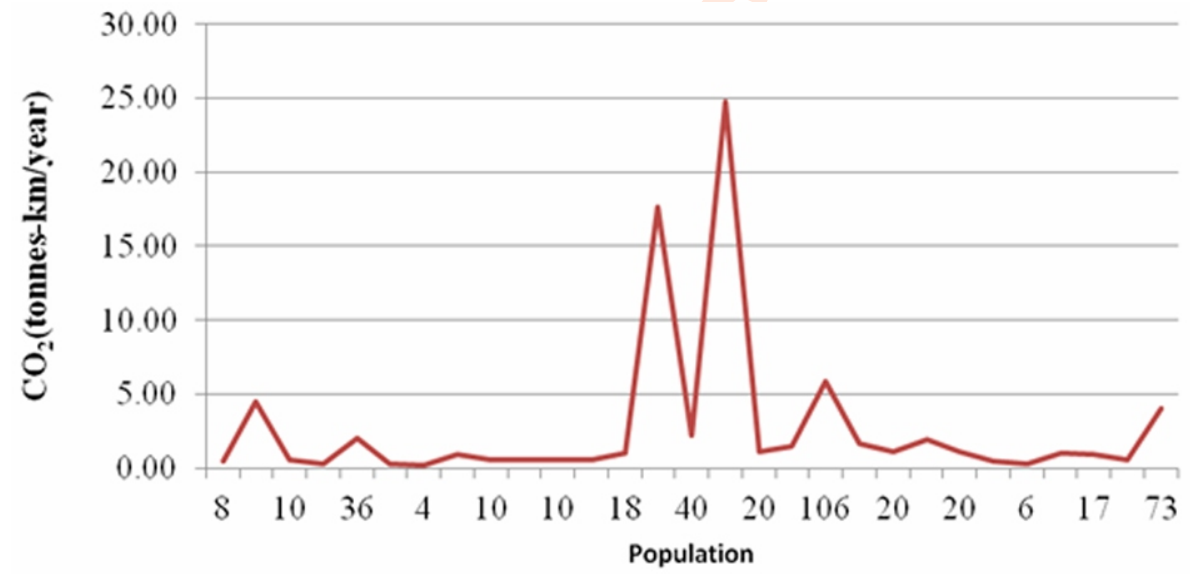

Fig. 3: Equivalent carbon dioxide emission from human population.

inferred that as the population increased the $\mathrm{CO}_{2}$ emission also increased drastically and vice-versa.

Vehicles were categorized according to their type and the average values of petrol and diesel consumed, mileage, distance travelled and $\mathrm{CO}_{2}$ emitted is presented in Fig. 4. The maximum $\mathrm{CO}_{2}$ emission was observed in bus (1.671 tonne sper year) and the minimum for two wheelers between 110 to $200 \mathrm{CC}$ (0.080 tonnes per year). The total Carbon emission from transport was estimated to be 36.43 tonnes per year. The total contribution from different sectors to carbon emission is given in Fig. 5. It can be inferred that emission from power use was higher in comparison with emission from transport, human population and diesel generators. This is in accordance with the study carried out by Letete et al. (2011). Letete et al. (2011 who had estimated carbon footprint for the year 2007 at University of Cape Town's and inferred that Electricity consumption alone contributed about $80 \%$ of all the emissions associated with university activities. A multiple linear regression equation was fitted by considering $\mathrm{CO}_{2}$ emitted as the dependant variable and electrical units consumed, human population, transport (mileage and distanced travelled) and diesel as independent variables and the results are presented in Table 2.

The mean units consumed, human population, mileage, distanced travelled, and diesel consumed was found to be 1180.000 (kWh per year), 47.600, $41.000\left(\mathrm{~km} \mathrm{l}^{-1}\right), 2625.980(\mathrm{~km}$ per year), 534.000 (L per year) with the standard eviation values of $7361.908,95.772,16.279,1725.069,244.049$ units respectively. Four regression equations were fitted by taking units, consumed, human population, transport (mileage and distanced travelled) and diesel as independent variables and $\mathrm{CO}_{2}$ emitted as dependent variable. The results showed that for a unit increase in units consumed, $\mathrm{CO}_{2}$ increased to 0.001 units and the following equation is $\mathrm{CO}_{2}$ emitted tonnes per year $=-0.002+$ 


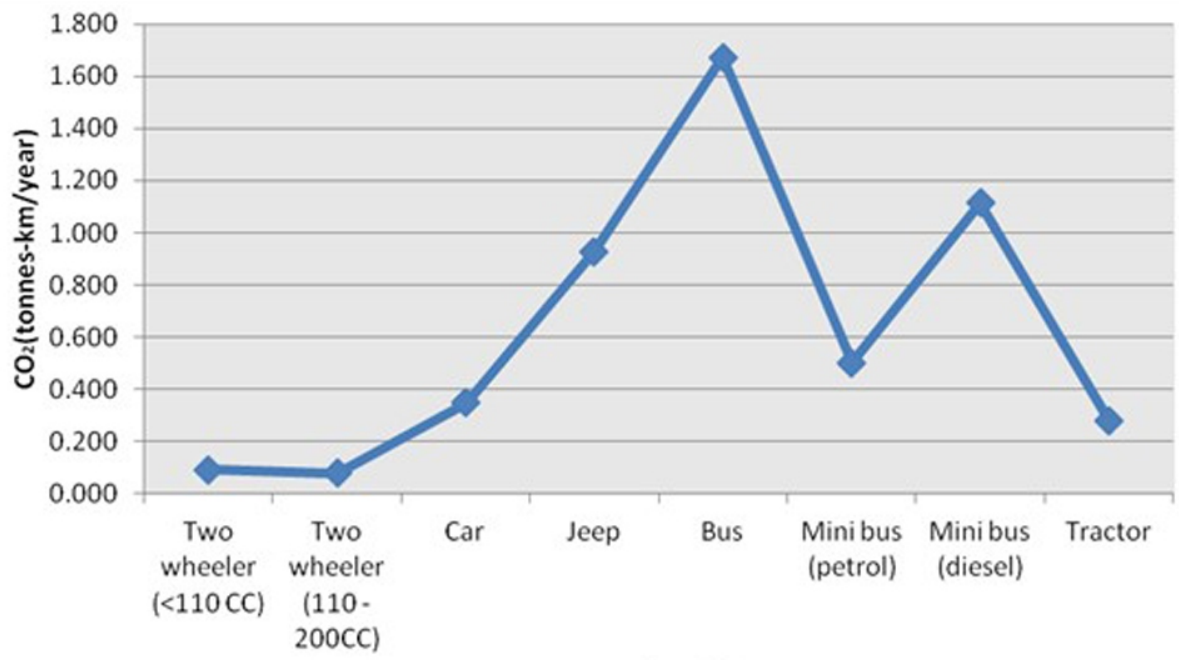

Type of Vechiles

Fig. 4: Equivalent carbon dioxide emission from vehicular transport.

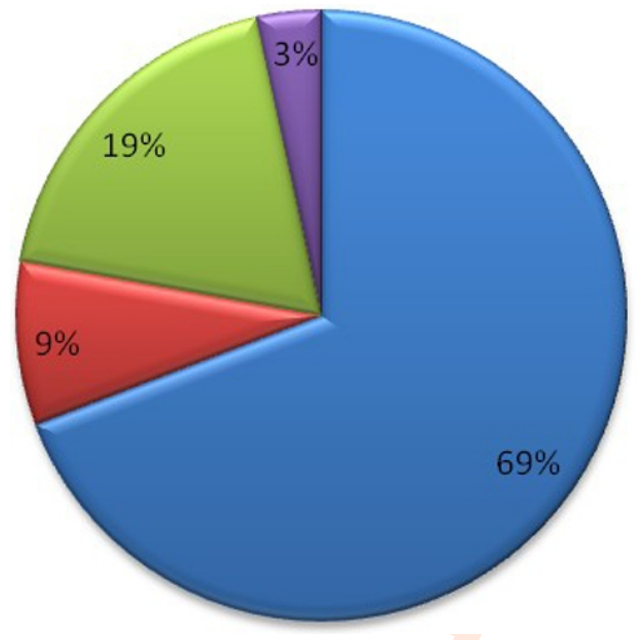

$\mathrm{CO}_{2}$ emission from power consumption (tonnes/year)

$\mathrm{CO}_{2}$ emission from transport (tonnes/year)

$\checkmark \mathrm{CO}_{2}$ emission from human population (tonnes/year)

$\square \mathrm{CO}_{2}$ emission from diesel generator (tonnes/year)

Fig. 5: Overall carbon dioxide emission from different sources.

0.001 units consumed per year For a unit increase in human population, $\mathrm{CO}_{2}$ emission increased to 0.055 units $\mathrm{CO}_{2}$ emitted tonnes per year $=-8.210 \mathrm{E}-16+0.055$ number of persons.

The results of regression analysis with mileage and distance travelled as independent variables showed that for a unit increase in the distance travelled the $\mathrm{CO}_{2}$ emission increased to $8.562 \mathrm{E}-5$ and for a unit increase in the mileage the $\mathrm{CO}_{2}$ emission decreased to 0.011 units. $\mathrm{CO}_{2}$ emitted tonnes per year $=0.402$ 0.011 mileage $\mathrm{km} \mathrm{l}^{-1}+8.562 \mathrm{E}-5$ distance travelled per year For a unit increase in the diesel consumed by diesel generator, the $\mathrm{CO}_{2}$ emission increased to 0.3 units $\mathrm{CO}_{2}$ emitted tonnes per year $=$

\section{$8.882 \mathrm{E}-16+0.003$ diesel consumed.}

It was inferred that emission from power use (69\%) was greater in comparison with emission from transport (9\%), human population (19\%) and diesel generators (3\%). Potential actions to mitigate emissions include increased energy conservation and efficiency, employment of renewable energy systems and use of alternative fuels. Other greenhouse gas mitigation options include sequestration of $\mathrm{CO}_{2}$ in biologic sinks such as plant biomass. The problem of anthropogenic $\mathrm{CO}_{2}$ accumulation in the atmosphere can be addressed either by reducing $\mathrm{CO}_{2}$ emission or by developing carbon sinks. 
Table 1: Comparison of fluorescent tube light and LED

\begin{tabular}{|c|c|c|c|c|c|c|}
\hline \multirow{2}{*}{ Buildings } & \multicolumn{2}{|c|}{$\begin{array}{l}\text { Electrical units used } \\
\text { (kWh per year) }\end{array}$} & \multicolumn{2}{|c|}{$\begin{array}{l}\mathrm{CO}_{2} \text { emitted } \\
\text { (tonnes per year) }\end{array}$} & \multirow[t]{2}{*}{$\begin{array}{l}\text { Units saved } \\
\text { (kWh per year) }\end{array}$} & \multirow{2}{*}{$\begin{array}{l}\mathrm{CO}_{2} \text { emission } \\
\text { reduction } \\
\text { (tonnes per year) }\end{array}$} \\
\hline & FTL & LED & FTL & LED & & \\
\hline Mushroom Research Training Centre & 1360.800 & 612.360 & 1.157 & 0.521 & 748.440 & 0.636 \\
\hline Agro Climate Research Center (ACRC) \& Press & 4859.400 & 2186.730 & 4.130 & 1.859 & 2672.670 & 2.272 \\
\hline Community Radio Station & 1050.000 & 472.500 & 0.893 & 0.402 & 577.500 & 0.491 \\
\hline Directorate of Open and Distance Learning (ODL) & 1890.000 & 850.500 & 1.607 & 0.723 & 1039.500 & 0.884 \\
\hline Agricultural Technology Information Center (ATIC) & 1008.000 & 453.600 & 0.857 & 0.386 & 554.400 & 0.471 \\
\hline Sustainable Laboratory & 252.000 & 113.400 & 0.214 & 0.096 & 138.600 & 0.118 \\
\hline Department of Sustainable Organic Agriculture & 1965.600 & 982.800 & 1.671 & 0.835 & 982.800 & 0.835 \\
\hline Technology Park 2 & 134.400 & 60.480 & 0.114 & 0.051 & 73.920 & 0.063 \\
\hline Technology Park 3 & 134.400 & 60.490 & 0.114 & 0.051 & 73.910 & 0.063 \\
\hline Technology Park 4 & 134.400 & 60.500 & 0.114 & 0.051 & 73.900 & 0.063 \\
\hline Technology Park 6 & 134.400 & 60.510 & 0.114 & 0.051 & 73.890 & 0.063 \\
\hline Physical Sciences and Information Technology & 6678.000 & 3005.100 & 5.676 & 2.554 & 3672.900 & 3.122 \\
\hline Agricultural Engineering College \& Research Institute & 9777.600 & 4399.920 & 8.311 & 3.740 & 5377.680 & 4.571 \\
\hline Water Technology Center (WTC) & 1512.000 & 680.400 & 1.285 & 0.578 & 831.600 & 0.707 \\
\hline Nematology & 1722.000 & 774.900 & 1.464 & 0.659 & 947.100 & 0.805 \\
\hline Pathology & 6115.200 & 2751.840 & 5.198 & 2.339 & 3363.360 & 2.859 \\
\hline Directorate of Agri Business Development & 3024.000 & 1360.800 & 2.570 & 1.157 & 1663.200 & 1.414 \\
\hline Technology Business Incubator & 2419.200 & 1088.640 & 2.056 & 0.925 & 1330.560 & 1.131 \\
\hline Bioenergy Workshop & 1932.000 & 869.400 & 1.642 & 0.739 & 1062.600 & 0.903 \\
\hline Food and Agricultural Pprocess Engineering Laboratory & 1386.000 & 623.700 & 1.178 & 0.530 & 762.300 & 0.648 \\
\hline Farm Machinery Workshop & 1764.000 & 793.800 & 1.499 & 0.675 & 970.200 & 0.825 \\
\hline Soil and Water Conservation Workshop & 2469.600 & 1111.320 & 2.099 & 0.945 & 1358.280 & 1.155 \\
\hline Radio Isotope Laboratory & 1201.200 & 540.540 & 1.021 & 0.459 & 660.660 & 0.562 \\
\hline Pesticide Toxicology Laboratory I & 714.000 & 321.300 & 0.607 & 0.273 & 392.700 & 0.334 \\
\hline Pesticide toxicology laboratory II & 201.600 & 90.720 & 0.171 & 0.077 & 110.880 & 0.094 \\
\hline Crop Physiology & 680.400 & 340.200 & 0.578 & 0.289 & 340.200 & 0.289 \\
\hline Total & 54520.200 & 24666.450 & 46.342 & 20.966 & 29853.750 & 25.376 \\
\hline
\end{tabular}

Table 2: Regression analysis for overall carbon emission

\begin{tabular}{llllll}
\hline & & & \multicolumn{2}{c}{ Transport } \\
\cline { 5 - 6 } Model & $\begin{array}{l}\text { Electricity } \\
\text { consumed } \\
\text { kWh per year }\end{array}$ & $\begin{array}{l}\text { Human } \\
\text { Population/ } \\
\text { day }\end{array}$ & $\begin{array}{l}\text { Mileage } \\
\mathbf{k m ~ I}^{-1}\end{array}$ & $\begin{array}{l}\text { Distance } \\
\text { travelled } \\
\text { (km per year) }\end{array}$ & $\begin{array}{l}\text { Diesel } \\
\text { generator }\end{array}$ \\
\hline Mean & 1180.000 & 47.600 & 41.000 & 2625.98 & 534.000 \\
Standard deviation & 7361.908 & 95.772 & 16.279 & 1725.069 & 244.049 \\
Constant & 0.002 & $8.210 \mathrm{E}-16$ & 0.402 & & $8.88 \mathrm{E}-16$ \\
Regression co-efficient values & 0.001 & 0.055 & 0.011 & $8.56 \mathrm{E}-05$ & 0.003 \\
\hline
\end{tabular}

\section{Acknowledgment}

Authors would like to acknowledge the support given by Tamil Nadu Agricultural University, Coimbatore for permitting to collect the data from various departments in the college.

\section{Add-on Information}

Authors' contribution: C.G. Karishma: Conceived and designed the analysis data collection, performed the analysis and wrote the paper; S.V. Kottiswaran: Technical guidance, supervised the research and contributed to final manuscript; $\mathbf{A}$. Balasubramanian: Technical guidance, supervised the research and contributed to the final manuscript; B. Kannan: Technical guidance, supervised the research and contributed to the final manuscript.

Research content: The research content of manuscript is 
original and has not been published elsewhere.

\section{Ethical approval: NotApplicable}

Conflict of interest: The authors declare that there is no conflict of interest.

\section{Data from other sources: NotApplicable}

Consent to publish: All authors agree to publish the paper in Journal of Environmental Biology.

\section{References}

Arora, V.P.S., S.S. Bargali and J.S. Rawat: Climate change: challenges, impacts, and role of biotechnology in mitigation and adaptation. Progres. Agricul., 11, 8-15 (2011).

Baboo, B., R. Sagar, S.S. Bargali and H. Verma: Tree species composition, regeneration and diversity within the protected area of Indian dry tropical forest. Tropi. Ecol., 58, 409-423 (2017).

Bargali, K., V. Manral, K. Padalia, S.S. Bargali and V.P. Upadhyay: Effect of vegetation type and season on microbial biomass carbon in Central Himalayan forest soils, India. Catena, 171, 125-135 (2018).

Bargali, S.S., K. Padalia and K. Bargali: Effects of tree fostering on soil health and microbial biomass under different land use systems in central Himalaya. Land Degrad. Develop., 30, 1984- 1998 (2019)

Bargali, S.S., R.P. Singh and M. Joshi: Changes in soil characteristics in eucalypt plantations replacing natural broad leaved forests. J. Veget. Sci., 4, 25-28 (1993).

Bargali, S.S., R.P. Singh and S.P. Singh: Structure and function of an age series of eucalypt plantations in Central Himalaya, II. Nutrient dynamics. Annals Bota., 69, 413-421 (1992).
Bargali, S.S., S.P. Singh and R.P. Singh: Structure and function of an age series of eucalypt plantations in Central Himalaya, I. Dry matter dynamics. Annals Bota., 69, 405-411 (1992).

Davidar, P., S. Sahoo, P.C. Mammen, P. Acharya, J.P. Puyravaud, M. Arjunan, J.P. Garrigues and K. Roessingh: Assessing the extent and causes of forest degradation in India: Where do we stand? Biol. Conserv., 143, 2937-2944 (2010).

Kittur, B., S.L. Swamy, S.S. Bargali and M.K. Jhariya: Wildland Fires and Moist Deciduous Forests of Chhattisgarh, India: Divergent ComponentAssessment. J. Fore. Res., 25, 857-866 (2014).

Letete, T.C., N.W., Mungwe, M. Guma and A. Marquard: Carbon footprint of the University of Cape Town. J. Ener. Southern Africa, 22,2-12 (2011).

Lynas, M.: Carbon Counter. Harper Collins Publishers, UK, Glasgow, UK (2007)

Manral, V., K. Bargali, S.S. Bargali and C. Shahi: Changes in soil biochemical properties following replacement of Banj oak forest with Chir pine in Central Himalaya, India. Ecol. Proce., 9, 30 (2020) https://doi.org/10.1186/s13717-020-00235-8.

Mary Lissy, P.N.: Carbon Footprint of an Educational Institution as a Technique for Sustainable Development. Int. J. Engine. Sci., 1, 196-200 (2012).

Pandey, D., M. Agrawa and J.S. Pandey: Carbon footprint: current methods of estimation. Environ. Monit. Assess., 178,135-160 (2011).

Sagar, R. and J.S. Singh: Local plant species depletion in a tropical dry deciduous forest of Northern India. Environ. Conserv., 31, 55-62 (2004).

Shailesh: Carbon Footprint Calculation- A small introduction of ISO 14064, Green Clean Guide, 1, 20 (2013).

Tukker, A. and B. Jansen: Environmental impacts of products: A detailed review of studies. J. Indus. Ecol., 10,159-182 (2006).

Utaraskul, T.: Carbon Footprint of Environmental Science Students in Suan Sunandha Rajabhat University, Thailand. Procedia-Social Behavi. Sci., 197,1156-1160 (2015). 